\title{
RANCANGAN ALAT INDIKATOR LEVEL TEGANGAN BATERAI BERBASIS OPERATIONAL AMPLIFIER (OP AMP)
}

\author{
Muh Pauzan \\ Teknik Komputer, Fakultas Teknik, Universitas Wiralodra \\ pauzan.muh@gmail.com
}

\begin{abstract}
ABSTRAK
Telah dilakukan rancangan alat indikator level tegangan dengan memanfaatkan operational amplifier (op amp) sebagai komparator. Alat yang dibuat digunakan untuk mengetahui level tegangan dua baterai Li-Ion $3.7 \mathrm{~V}$ yang disusun seri. Tegangan habis (end voltage) untuk dua baterai adalah $6 \mathrm{~V}$ dan tegangan maksimumnya $8.4 \mathrm{~V}$. Tapi pada alat yang dibuat ditentukan $8 \mathrm{~V}$ sebagai tegangan maksimum. Terdapat empat indikator, pertama indikator LED merah untuk 25\% (6.5V) tegangan baterai, LED kuning untuk 50\% (7V), LED hijau untuk 75\% (7.5V) dan LED biru untuk 100\% (8V) tegangan baterai. LED akan menyala jika output op amp adalah high. Output high terjadi jika tegangan masuk $V_{\text {in }}$ yang melalui pin 2 lebih besar daripada tegangan referensi $V_{\text {ref }}$ pada pin 3 op amp. Dilakukan perhitungan secara teoritis kemudian dibuat rangkaiannya menggunakan software Proteus.
\end{abstract}

Kata Kunci: operational amplifier, baterai, komparator, Proteus.

\section{ABSTRACT}

A voltage level indicator have been built by using of operational amplifier (op amp) as comparator. The device is used to know the level voltage of two Li-Ion Battery $3.7 \mathrm{~V}$ in series configuration. The batteries have $6 \mathrm{~V}$ end voltage and $8.4 \mathrm{~V}$ maximum voltage. But $8 \mathrm{~V}$ maximum voltage is used in the device. There are four level indicator; a red LED for 25\% (6.5V) of maximum voltage, a yellow LED for $50 \%$ (7V), a green LED for $75 \%(7.5 \mathrm{~V})$ and a blue LED for 100\% (8V) of battery's voltage. LED would glow if $V_{\text {in }}$ through pin 2 is greater than $V_{\text {ref }}$ through pin 3 on op amp. Theoretical calculation have beenstudied before creating the circuit by Proteus software.

Keywords: operational amplifier, battery, comparator, Proteus.

\section{PENDAHULUAN}

Operational amplifier (Op amp) merupakan komponen aktif yang berfungsi sebagai operasi matematik pada suatu tegangan listrik seperti penjumlahan, pengurangan, perkalian, pembagian, pengintegralan, penurunan serta pembanding (komparator) [1]. Op amp banyak diterapkan pada rangkaian-rangkaian analog listrik seperti sebagai penguat tegangan, penjumlahan dua sumber tegangan, penguat selisih antara dua tegangan dan lain-lain.

Cara kerja op amp sebagai komparator adalah op amp diberikan tegangan masuk $V_{\text {in }}$ melalui pin 2, sedangkan pin 3 dijadikan sebagai tegangan pembandingnya $\left(V_{\text {ref }}\right)$. Jika $V_{\text {in }}<V_{\text {ref }}$ maka output (melalui pin 6) adalah 0 , sedangkan jika $V_{\text {in }}>V_{\text {ref }}$ maka outputnya sama dengan $V_{c c}$. Salah satu aplikasinya yaitu op amp digunakan sebagai indikator level tegangan baterai.

Gadgettronicx [2] merangkai alat indikator level tegangan pada baterai laptop (12V Baterai Li-Ion). Digunakan 4 op amp karena terdapat 4 level indikator tegangan yaitu: $25 \%, 50 \%, 75 \%$ dan $100 \%$ tegangan baterai. Output op amp dihubungkan dengan LED dengan ketentuan LED warna merah untuk tegangan $25 \%$, warna kuning untuk level tegangan $50 \%$, warna hijau untuk level tegangan $75 \%$ dan warna biru untuk level tegangan $100 \%$. Dioda zener 1N47333A yang memiliki tegangan nominal $5.1 \mathrm{~V}$ digunakan sebagai regulator tegangan dan dihubungkan dengan pin 2 op amp. Powergen522 [3] juga merangkai alat indikator level tegangan untuk $12 \mathrm{~V}$ baterai Li-Ion namun IC yang digunakan adalah LM3915.

Pada situs instructables [4] digunakan IC op amp LM339N sebagai komparator untuk $3.7 \mathrm{~V}$ baterai Li-Ion. Digunakan tegangan referensi $4.2 \mathrm{~V}$ untuk indikator tegangan $100 \%$. $4.2 \mathrm{~V}$ adalah tegangan maksimum baterai [5] sehingga jika dicas pada waktu yang relatif lama pada kondisi penuh maka akan menimbulkan panas sehingga akan memperpendek waktu pakai baterai tersebut. 
Berdasarkan referensi yang disajikan, penulis mencoba untuk merancang alat indikator level tegangan 2 baterai Li-Ion $3.7 \mathrm{~V}$ yang disusun seri. Dipilih rangkaian seri karena alat-alat elektronika yang digunakan sehari-hari banyak yang memakai 2 baterai bahkan lebih seperti remote control mobil mainan, remote control drone dan lainlain. Hal lain yang diperhatikan adalah supaya waktu pengisian baterai lebih pendek karena 2 baterai diisi secara bersamaan. Pada perancangan sistem ini juga diberikan indikator baterai penuh saat tegangan kedua baterai pada $8.0 \mathrm{~V}$, tidak digunakan pada tegangan maksimum $8.4 \mathrm{~V}$ karena hal tersebut akan mempercepat waktu pakai baterai sehingga baterai tidak tahan lama. Agar supaya saat tegangan mencapai $8.0 \mathrm{~V}$ diketahui maka ditambahkan buzzer pada rangkaian. Buzzer berfungsi mengeluarkan suara saat baterai yang dicas penuh. Digunakan 4 indikator nyala lampu: LED merah untuk 25\%, LED kuning untuk 50\%, LED hijau untuk $75 \%$ dan LED biru untuk $100 \%$ tegangan. Alat didesain menggunakan software Proteus. Fokus penelitian ini adalah membandingkan parameter-parameter seperti tegangan dan arus secara perhitungan teori dengan hasil dari simulasi proteus.

\section{METODE PENELITIAN}

Perancangan alat Indikator level tegangan baterai dengan software proteus ini menggunakan komponen-komponen sebagai berikut:

* Resistor

* Kapasitor

- IC741 (Op Amp)

* LED

* Dioda Si 1N4001

Proteus digunakan untuk merancang dan simulasi rangkaian, hal ini dilakukan sebagai cara untuk memastikan bahwa alat yang dibuat dapat beroperasi sebagaimana yang diinginkan. Pada proteus juga bisa dibuat rangkaiannya pada papan PCB (Printed Board Circuit).

\section{A. Perancangan Sistem}

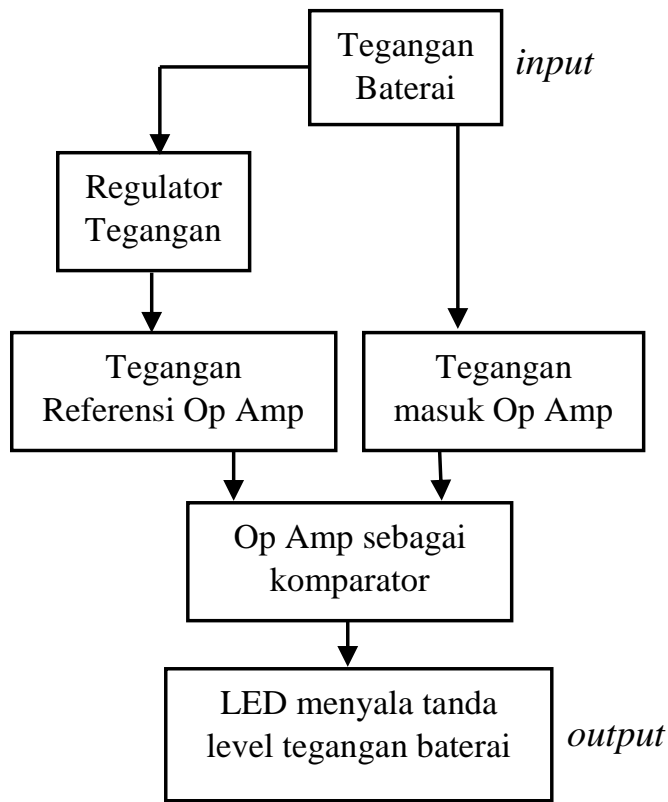

Gambar 1. Blok perancangan alat indikator level tegangan

\section{B. Algoritma Sistem}

Algoritma adalah rangkaian-rangkaian yang dilakukan oleh sistem, dimulai dari input sampai dengan output. Algoritma alat indikator level tegangan yang dirancang adalah sebagai berikut:

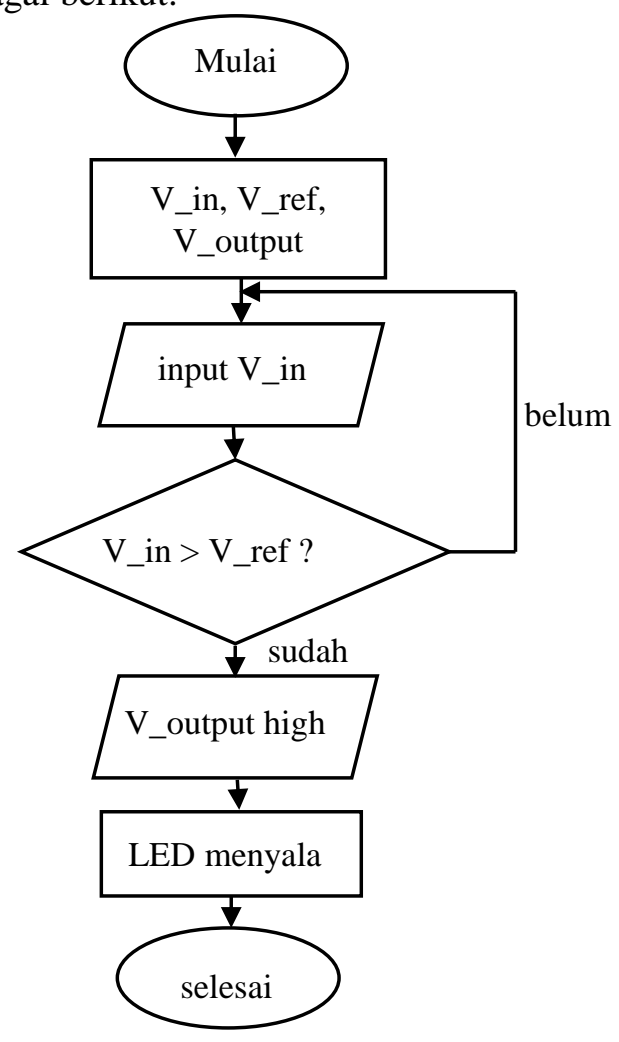

Gambar 2. Proses LED menyala sebagai indikator level tegangan baterai 


\section{Diagram Rangkaian}

Rangkaian lengkap alat indikator level tegangan baterai menggunakan Proteus dapat dilihat pada gambar di bawah:

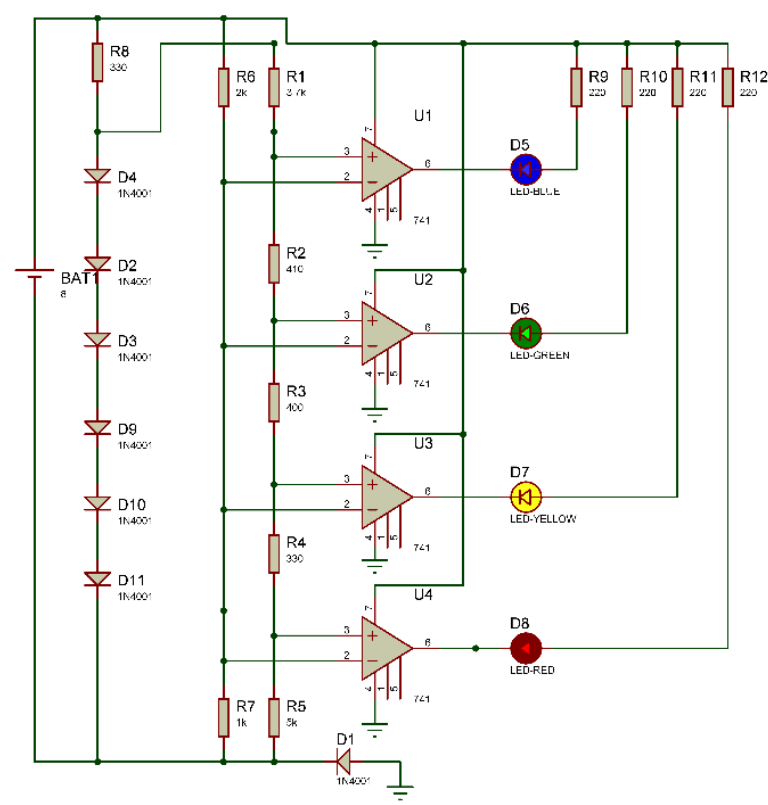

Gambar 3. Rangkaian alat indikator level tegangan baterai

\section{HASIL DAN PEMBAHASAN}

Perancangan alat indikator level tegangan baterai melalui beberapa tahap yaitu tahap perhitungan teori dan kemudian perancangannya pada software Proteus.

\section{A. Perhitungan teoretik}

Dua buah baterai Li-Ion masing-masing 3.7V dirangkai seri seperti pada gambar di bawah ini:

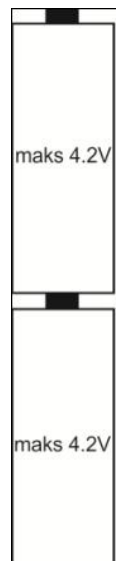

Gambar 4. Dua baterai Li-Ion 3.7V dirangkai seri

Satu baterai Li-Ion memiliki tegangan maksimum 4.2V [6] maka untuk dua buah baterai dirangkai seri memiliki tegangan maksimum $8.4 \mathrm{~V}$. Alat yang dibuat disetting tegangan maksimumnya pada $8.0 \mathrm{~V}$ hal ini dilakukan supaya baterai memiliki lifetime yang lebih lama.Sebuah baterai Li-Ion memiliki tegangan habis (end voltage) $3.0 \mathrm{~V}$ artinya jika baterai digunakan terus-menerus maka alat yang digunakan akan mati saat tegangan baterainya mencapai 3.0 volt. Oleh karena itu pada rancangan alat ini, ditentukan tegangan minimal untuk dua baterai adalah 3 $+3=6$ volt. Jadi rentang tegangan dari indikator baterai $0 \%$ sampai dengan $100 \%$ adalah dari $6 \mathrm{~V}-8 \mathrm{~V}$. Penulis membagi level tegangan menjadi 4 sehingga tiap kenaikan 0.5 volt tegangan baterai bertambah $25 \%$. Tabel berikut menjelaskan level tegangan dengan LED sebagai indikatornya:

Tabel 1. Hubungan level tegangan dengan nyala LED sebagai indikator

\begin{tabular}{|c|c|c|}
\hline Tegangan & Dalam \% & Indikator \\
\hline $8 \mathrm{~V}$ & $100 \%$ & LED biru on \\
\hline $7.5 \mathrm{~V}$ & $75 \%$ & LED hijau on \\
\hline $7 \mathrm{~V}$ & $50 \%$ & LED kuning on \\
\hline $6.5 \mathrm{~V}$ & $25 \%$ & LED merah on \\
\hline
\end{tabular}

Regulator tegangan yang digunakan adalah 6 buah dioda silikon yang memiliki total tegangan 4.2 volt. Dioda silikon digunakan karena tidak ada di pasaran dioda zener yang memiliki tegangan nominal 4.2 volt, biasanya 5.1 volt, 10 volt dan seterusnya.4.2 $\mathrm{V}$ adalah tegangan input pada $V_{\text {REF }}$ maka tegangan masukan ke $V_{\text {in }}$ harus lebih kecil dari $4.2 \mathrm{~V}$, maka digunakan rumus sebagai berikut:

Tabel 2. Pembagi tegangan $8 \mathrm{~V}$ pada baterai

\begin{tabular}{|l|c|c|}
\hline Persentase & Perkalian & $V_{\text {in }}(\mathrm{V})$ \\
\hline $100 \%$ & $8 \times \frac{1}{3}$ & 2.67 \\
\hline $75 \%$ & $7.5 \times \frac{1}{3}$ & 2.50 \\
\hline $50 \%$ & $7 \times \frac{1}{3}$ & 2.33 \\
\hline $25 \%$ & $6.5 \times \frac{1}{3}$ & 2.17 \\
\hline
\end{tabular}

Tegangan referensi untuk setiap IC op amp (IC741) harus lebih kecil daripada tegangan input pada tabel 2 di atas.

Berdasarkan tabel 2 di atas maka ditentukan nilai $V_{\text {ref }}<V_{\text {in }}$ untuk tiap 
persentase tegangan. $V_{\text {ref }}$ untuk tegangan 100\% adalah:

$V_{\text {ref } 1}<2.67$ maka diatur $V_{\text {ref }}=2.65 \mathrm{~V}$.

$$
\begin{array}{r}
2.65=\frac{R_{2}+R_{3}+R_{4}+R_{5}}{R_{\text {tot }}} V_{\text {ref }} \\
2.65=\frac{R_{2}+R_{3}+R_{4}+R_{5}}{R_{\text {tot }}} 4.2 \\
R_{2}+R_{3}+R_{4}+R_{5}=0.631 R_{\text {tot }} \ldots
\end{array}
$$

Begitu juga dengan $V_{\text {ref } 2}$ untuk tegangan $75 \%, V_{\text {ref2 }}<2.5$ maka ditentukan $V_{\text {ref } 2}=$ 2.48;

$$
\begin{array}{r}
2.48=\frac{R_{3}+R_{4}+R_{5}}{R_{\mathrm{tot}}} V_{\text {ref }} \\
2.48=\frac{R_{3}+R_{4}+R_{5}}{R_{\mathrm{tot}}} 4.2 \\
R_{3}+R_{4}+R_{5}=0.59 R_{\mathrm{tot}} \ldots
\end{array}
$$

Sedangkan untuk $V_{\text {ref } 3}$ dengan tegangan 50\% harus memiliki nilai $<2.33 \mathrm{~V}$ maka:

$$
\begin{aligned}
2.31 & =\frac{R_{4}+R_{5}}{R_{\text {tot }}} V_{\text {ref }} \\
2.31 & =\frac{R_{4}+R_{5}}{R_{\text {tot }}} 4.2 \\
R_{4}+R_{5} & =0.55 R_{\text {tot }} \ldots
\end{aligned}
$$

Level tegangan $25 \%$ memiliki $V_{\text {in }}=2.17 \mathrm{~V}$ maka $V_{\text {ref } 4}$ ditentukan sebesar $2.15 \mathrm{~V}$;

$$
\begin{gathered}
2.15=\frac{R_{5}}{R_{\text {tot }}} V_{\text {ref }} \\
2.15=\frac{R_{5}}{R_{\text {tot }}} 4.2 \\
R_{5}=0.5119 R_{\text {tot }} \ldots
\end{gathered}
$$

Dengan memberikan nilai $R_{5}=5 \mathrm{k} \Omega$ maka diperoleh: $R_{4}=330 \Omega, \quad R_{3}=400 \Omega$, $R_{2}=410 \Omega$ dan $R_{1}=3,7 \mathrm{k} \Omega$. Nilai-nilai $R$ tersebut dimasukkan pada rangkaian gambar 2.3 di atas.

\section{B. Perancangan pada Proteus}

Setelah melakukan kalkulasi secara teori, dibuat rangkaian alat menggunakan Proteus seperti yang ditunjukkan pada gambar 3 untuk menguji apakah perhitungan secara teori sesuai dengan simulasi maka dilakukan variasi tegangan baterai yaitu pada persentase $25 \%$ yaitu $6.5 \mathrm{~V}, 50 \%$ yaitu $7 \mathrm{~V}$, $75 \%$ pada $7.5 \mathrm{~V}$ dan $100 \%$ pada $8 \mathrm{~V}$. Hasil simulasinya adalah sebagai berikut:

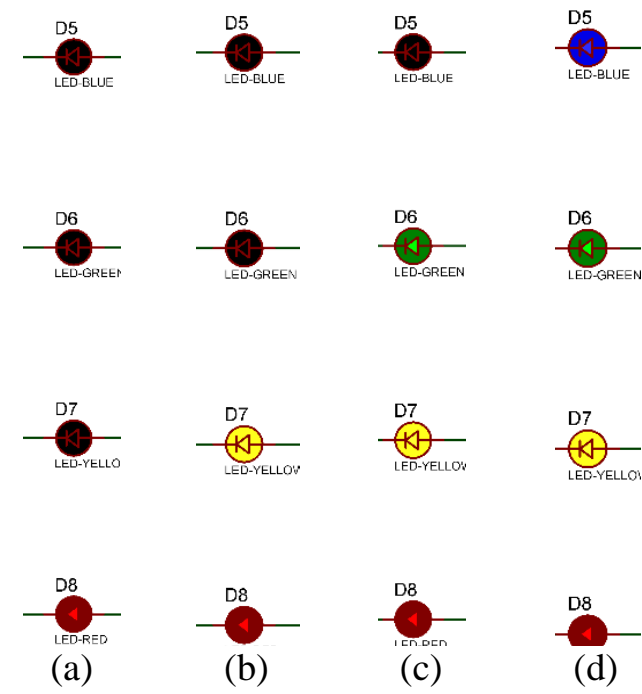

Gambar 5 (a) saat tegangan 25\% (b) 50\% (c) $75 \%$ dan (d) $100 \%$

Berdasarkan hasil simulasi Proteus pada gambar 5 di atas, LED merah menyala saat tegangan baterai $6.5 \mathrm{~V}$, LED kuning (dan merah) menyala saat tegangan $7 \mathrm{~V}$, LED hijau (merah dan kuning) menyala saat tegangan $7.5 \mathrm{~V}$ serta LED biru (merah, kuning dan hijau) menyala saat tegangan $8 \mathrm{~V}$. Oleh karena itu dapat disimpulkan bahwa perancangan secara teoretik tepat sehingga hasilnya sesuai dengan nyala LED untuk tiap-tiap persentase tegangannya.

\section{KESIMPULAN}

Kesimpulan dari rancangan alat yang dibuat adalah sebagai berikut:

1. Dioda Silikon bisa digunakan sebagai regulator pengganti dioda zener tegangan jika nilai tegangan yang diinginkan tidak ada pada dioda zener

2. Konsep pembagi tegangan sangat penting dalam menentukan $V_{\text {in }}$ dan $V_{\text {ref }}$

3. Perhitungan teoretik dengan simulasi menggunakan Proteus memiliki hasil yang sama.

\section{DAFTAR PUSTAKA}

[1] Learn.adafruit. 2019. "end voltage of LiIon".

https://learn.adafruit.com/li-ion-andlipoly-batteries?view=all

Diakses pada 12 Februari 2019

[2] gadgetronicx. 2019. "battery level indicator".

https://www.gadgetronicx.com/batterycharge-indicator-circuit-diagram/ 
Diakses pada 12 Februari 2019

[3] powergen522.blogspot. 2018. "battery voltage level indicator". https://www.owergen522.blogspot.com/ 2018/02/12v-battery-voltage-levelindicator-and.html Diakses pada 12 Februari 2019

[4] instructables. 2019. "battery level indicator".

https://www.instructables.com/id/LiIon-battery-level-indicator/ Diakses pada 12 Februari 2019

[5] batteryuniversity. 2019. "how to make battery long lifetime". https://batteryuniversity.com/learn/articl e/do_and_dont_battery_table Diakses pada 12 Februari 2019

[6] Datasheet. 2010. Lithium-Ion Battery. EEMB Co,.Ltd. 
Halaman ini sengaja dikosongkan 